\title{
Thermal ablation of mucosal defect margins reduces adenoma recurrence after colonic endoscopic mucosal resection
}

\author{
Çağlayan Keklikkıran, Osman Cavit Özdoğan (1) \\ Department of Gastroenterology, Marmara University Pendik Research and Training Hospital, Istanbul, Turkey
}

Cite this article as: Keklikkıran Ç, Özdoğan OC. Thermal ablation of mucosal defect margins reduces adenoma recurrence after colonic endoscopic mucosal resection. Turk J Gastroenterol 2019; 30(6): 580-1.

Klein A, Tate DJ, Jayasekeran V, et al. Thermal ablation of mucosal defect margins reduces adenoma recurrence after colonic endoscopic mucosal resection. Gastroenterology 2019; 156: 604-13.e3.

Colorectal cancer (CRC) is the third most common cancer as well as the second leading cause of cancer-related deaths globally (1). In Turkey, CRC is the third most common cancer at all ages among both sexes (2). Colonoscopy with polypectomy, which is a very effective method for $\mathrm{CRC}$ screening and prevention, can reduce the incidence of CRC by $76 \%-90 \%$ in appropriately screened individuals (3). Approximately $5 \%$ of colonic polyps are lateral spreading lesions (LSL) $\geq 10 \mathrm{~mm}$ in size that grow through the bowel walls. Large LSLs ( $\geq 20 \mathrm{~mm}$ ) are known highrisk precursors of CRC. EMR is a well-established and safe surgical alternative for colonic mucosal lesions. However, recurrence at the polypectomy site is a major concern after standard polypectomies because of the lack of complete resection (4).

In the February 2019 issue of Gastroenterology, Klein et al. published an article on thermal ablation of mucosal defect margins after colonic endoscopic mucosal resection. This was a prospective, multicenter study with 1:1 randomization that was conducted by 11 endoscopists who had been trained for colonic EMR for at least 12 months at four Australian tertiary centers. The investigators enrolled patients with colonic $L S L \geq 20 \mathrm{~mm}$, whereas the exclusion criteria were incomplete snare excision; LSL located at the ileo-cecal valve, appendiceal orifice, and fully circumferential lesions; and previously attempted LSL. Standardized injection and resection methods were used for the excision of the polyps, followed by resection snare tip soft coagulations applied to the margins. Two surveillance colonoscopies were planned at 5-6 months and 18 months after the index procedure. Endoscopic adenoma recurrence at the first colonoscopic surveillance was the primary endpoint of study.
In total, 390 patients with 416 lesions (206 lesions in control group and 210 lesions in active group) were included in the study. Age, sex, lesion location, lesion size, and EMR duration were similar in both groups. Endoscopic recurrence rates were found to be $5.2 \%(10 / 192)$ in the active arm and $21 \%(37 / 176)$ in the control arm at the first surveillance procedure. Histologic recurrence rates were $4.7 \%$ in the active arm and $22.9 \%$ in the control arm groups. Comparison of en-bloc or piecemeal resection and lesion size to the recurrence rates between the groups revealed that the control group had higher recurrence rates when lesions were resected piecemeal compared with that for en-bloc resection $(24.2 \%$ vs. $0 \%)$; however, the active arm recurrence rates were similar between the groups $(5.4 \%$ vs. $4 \%, p=1)$. Additionally, recurrence rates after piecemeal resection in the control group were significantly higher than those in the active group $(24.2 \%$ in the control arm vs. $5.4 \%$ in the active arm, $\mathrm{p}<0.001$ ). With respect to polyp sizes $\geq 40$ and $<40 \mathrm{~mm}$, the recurrence rates were significantly higher for lesions $\geq 40 \mathrm{~mm}$ in the control group ( $<40 \mathrm{~mm}: 11.8 \% \mathrm{vs}, \geq 40 \mathrm{~mm}: 36.4 \%$, $\mathrm{p}<0.001$ ). Polyps $\geq 40 \mathrm{~mm}$ in the active arm had significantly less recurrence rates compared with those in the control group (3.3\% vs. $36.4 \%, p=0.001)$. However, there was no significant difference in lesions $<40 \mathrm{~mm}$ between the active and control arms (6.1\% vs. $11.8 \%, p=0.1)$

In conclusion, it appears that this study is promising and a possible candidate for changing our practices. The methodology, sample size with adequate power, randomized nature of the study, and multicentricity are powerful features of this study. The authors found a 4-fold decrease in adenoma recurrence rates in first surveillance endoscopy with the use of thermal ablation compared with the recurrence rates obtained in larger studies (5.2\% vs. $15-30 \%)(5,6)$. This finding shows that if validated with further trials, it will reduce the number of recurrent endoscopic procedures, increase patient compliance, and reduce the financial burden on healthcare systems. 


\section{REFERENCES}

1. Ferlay J, Colombet M, Soerjomataram I, et al. Estimating the global cancer incidence and mortality in 2018: GLOBOCAN sources and methods. Int J Cancer 2019; 144: 1941-53. [CrossRef]

2. Türkiye Kanser İstatistikleri. 2017; Available from: https://hsgm. saglik.gov.tr/depo/birimler/kanser-db/istatistik/2014-RAPOR. uzuuun.pdf

3. Winawer SJ, Zauber AG, Ho MN, et al. Prevention of Colorectal Cancer by Colonoscopic Polypectomy. N Engl J Med 1993; 329: 1977-81. [CrossRef]
4. Belderbos TDG, Leenders M, Moons LMG, Siersema PD. Local recurrence after endoscopic mucosal resection of nonpedunculated colorectal lesions: systematic review and meta-analysis. Endoscopy 2014; 46: 388-402. [CrossRef]

5. Buchner AM, Guarner-Argente C, Ginsberg GG. Outcomes of EMR of defiant colorectal lesions directed to an endoscopy referral center. Gastrointest Endosc 2012; 76: 255-63. [CrossRef]

6. Knabe M, Pohl J, Gerges C, Ell C, Neuhaus H, Schumacher B. Standardized long-term follow-up after endoscopic resection of large, nonpedunculated colorectal lesions: a prospective two-center study. Am J Gastroenterol 2014; 109: 183-9. [CrossRef] 